\title{
Investigation of the Multicultural Perception Levels of Pre-service Physical Education Teachers: The Case of Western Black Sea
}

\author{
Isa Dogan \\ Hasan Doğan Physical Education and Sports, Karabük University, Turkey.
}

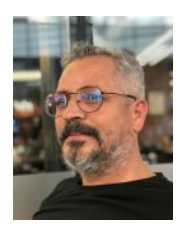

Abstract

The aim of the current study is to examine the multicultural perception levels of pre-service physical education teachers. In the scope of the study, it was also examined whether the preservice teachers' multicultural perception levels differ according to their university, gender, family income level, grade level and general academic achievement grade point average. In this direction, the universities in the Western Black Sea Region were selected and 407 pre-service teachers were interviewed. In the study, which was conducted in a screening design, one of the quantitative research methods, the data were collected with Multicultural Perception Scale developed by Ayaz (2016). The data of the research were analyzed with descriptive statistics, $t$ test for unrelated measurements and Kruskal Wallis test. As a result of the study, it was determined that pre-service teachers' perceptions of multiculturalism were high. While It was determined that pre-service teachers' perceptions of multiculturalism did not show a significant change according to their gender and grade levels, there were significant differences according to the university, general academic achievement grade point average and the income level of their families.

Keywords: Pre-service physical education teacher, Western Black Sea region, Multiculturalism, Multicultural perception, Education, Gender.

Citation | Isa Dogan (2020). Investigation of the Multicultural Perception Levels of Pre-service Physical Education Teachers: The Case of Western Black Sea. Asian Journal of Education and Training, 6(2): 122-129.

History:

Received: 29 November 2019

Revised: 20 January 2020

Accepted: 24 February 2020

Published: 16 March 2020

Licensed: This work is licensed under a Creative Commons

Attribution 3.0 License $(\mathrm{coc})$ )

Publisher: Asian Online Journal Publishing Group
Funding: This study received no specific financial support

Competing Interests: The author declares that there are no conflicts of interests regarding the publication of this paper.

Transparency: The author confirms that the manuscript is an honest, accurate, and transparent account of the study was reported; that no vital features of the study have been omitted; and that any discrepancies from the study as planned have been explained.

Ethical: This study follows all ethical practices during writing.

\section{Contents}

1. Introduction

References. 


\section{Contribution of this paper to the literature}

This study contributes to existing literature by examining the multicultural perception levels of pre-service physical education teachers.

\section{Introduction}

The Turkish Language Institution defines the word culture as the totality of all material and spiritual values created in the historical, social development process and the means used to convey these to the next generations in creating them and showing the measure of human sovereignty to the natural and social environment. In short, culture which can be expressed as the material and non-material values of a society contains language, religion, history, geography, art etc. When evaluated in this context, multiculturalism can be expressed as the coexistence of elements such as different languages, religions, history, geography, art, and enrichment of elements instead of conflict. Uygur (1996) also defines the concept of multiculturalism as the coexistence of different cultures in public sphere. It is seen that there are different cultures within the scope of multiculturalism which can be defined as living together equally and peacefully among different cultures (Parekh, 2002) emphasizing that these cultures can live together and are equal. Although there is difference in the place of multiculturalism, it is not a conflict but a mosaic that complements each other. Because, as a result of the fact that cultures are equal to each other and do not try to gain superiority, people in different cultures will be able to maintain their unique identities and survive in all areas (Ates, 2017).

Within the concept of multiculturalism, although the ethnic origins of individuals are overweight, the concept includes many differences such as religious, sexual, status etc. (Bahadır, 2016). Multiculturalism should be adopted as a policy in countries like Turkey which has hosted many civilizations in history, where different social groups come together, and people from many cultures. Because the world is getting smaller, different cultures and identities come together easily. Achieving belonging to different groups throughout the country and ensuring peace and tranquility in society depends on the effective implementation of multicultural policies (Gonzalez, 2008). Because the basis of multiculturalism is that all cultures live without conflict.

It is important that multiculturalism is reflected in the education environment as well as adopting a policy in terms of management throughout the country. Ensuring equality of opportunity in education which can be defined as the process of acquiring desired behaviors to individuals (Ertürk, 1997) students should not be privileged or disadvantaged depending on their characteristics such as language, religion and race (Banks, 2014). Similarly, multicultural education is not only for students belonging to different ethnic groups, social classes and religion; students with different gender, gifted and talented (Cirlk, 2008). Kaya and Aydın (2013) state that, thanks to multicultural education, groups with different cultural characteristics in the same classroom and school will receive equal and fair education and have similar academic opportunities. It emphasizes that multicultural education should be adopted as an educational philosophy. With this philosophy, there is an understanding that each culture is special and it is wrong to compare it with the values of other cultures (Portera, 2008). In an educational institution that adopts this philosophy, equal education is offered to each individual and students can also gain the ability to respect each other, to put themselves in the place of their friends and to treat them with tolerance (Bahadır, 2016).

Based on the definitions, students should respect and accept each other in multicultural education; it is seen that the teacher does not discriminate among the people due to the cultural difference and focuses on the aims of education by accepting everyone. Teachers need to diversify their teaching methods in the context of multiculturalism by directing students to the center (Başbay \& Kağnıcı, 2011). In this way, students will not take a discriminatory attitude away from prejudices (Ayaz, 2016). As can be seen, the responsibility of many stakeholders in reflecting the multicultural education understanding in the school and classroom environment is the most important task for teachers. Banks. (1993) found that multicultural education; It states that there are five dimensions of content integration, knowledge building process, reduction of prejudices, egalitarian education and empowering school culture, and teachers and education programs have an important responsibility in all of these dimensions. In this direction, the attitudes and perceptions of teachers about this issue come to the forefront during the success of multicultural education. As a matter of fact, teachers are expected to have a sense of multiculturalism themselves first and then to create a democratic environment in this context in their classroom. This is a skill that should be gained to the pre-service teachers in universities during the preparation stage of teaching.

In the literature, studies conducted with teachers from different branches, especially social studies teachers (Akman \& Imamoğlu, 2017; Aslan \& Kozikoğlu, 2017; Bahadır, 2016; Kaya \& Aydın, 2013; Mazı, 2018; Toprak, 2008) as well as with pre-service teachers (Arsal, Mumcu, \& Akçaoğlu, 2017; Koçak \& Ozdemir, 2015). Karaçam and Koca (2012) also conducted a qualitative research on the multicultural perceptions of pre-service physical education teachers. However, the number of studies on physical education teachers and pre-service teachers was found to be low in the literature and it was found that there was no general screening by reaching large sample groups.

Accordingly, the following questions were sought in the research:

- What is the level of multicultural perceptions of pre-service physical education teachers in the Western Black Sea Region?

- What is the level of multicultural perceptions of pre-service pre-service physical education teachers studying in the Western Black Sea Region (according to the university, gender, family income level, class level and general academic achievement grade average)?

\section{Method}

In this part of the research, information about the model of the research, population and sample, data collection tools, data collection and analysis are given. 


\subsection{Research Model}

Karasar (2008) states that screening research aims to describe a past or present situation as it exists. The main purpose of screening research is to describe the characteristics of a group (Frankel \& Wallen, 2009). In this study, as it is aimed to reveal and examine the multicultural perception levels present in pre-service physical education teachers, the research is an example of a quantitative research method.

\subsection{Population and Sample}

The population of the research consists of the pre-service physical education teachers studying in the physical education and teaching department of the universities in the Western Black Sea Region. Within the scope of the research, selection was made based on purposive stratified sampling method. In this respect, the universities in the universe were grouped first. There are a total of eight provinces in the Western Black Sea Region, namely Bartin, Bolu, Cankiri, Duzce, Karabuk, Kastamonu, Sinop and Zonguldak. There is one state university in each province. Sinop University in Sinop and Çankırı Karatekin University in Çankırı do not have any physical education department. In this respect, the students of Bartın University, Abant İzzet Baysal University, Düzce University, Karabük University, Kastamonu University and Bülent Ecevit University are the students of the Department of Physical Education. The sample of the study consists of students who can be reached from these universities. Lack of access to pre-service teachers studying at Düzce University is a limitation of the research.

Within the scope of the research, firstly, the universe number was reached and it was determined that 632 preservice teachers were educated in physical education teaching in these universities. Equality proposed by Büyüköztürk, Cakmak, Akgün, Karadeniz, and Demirel (2018) was used to determine the sample size representing the universe.

$$
=\frac{n_{0}}{1+\frac{n_{0}}{N}} \mathrm{n}
$$

Calculated as $\mathrm{n}_{0}=\left(\mathrm{t}^{2} \mathrm{PQ}\right) / \mathrm{d}^{2}$ equation in the equation and $\mathrm{p}$ significance value $0.05, \mathrm{pq}=0.25$ and the corresponding $t$ value in the table is $1.96 \mathrm{n}_{0}=0.05$ significance level 384,16 (Büyüköztürk et al., 2018). After equality, it was determined that at least 239 people represented the universe. It can be said that 407 pre-service teachers reached a high level of representation in the universe.

Information about the characteristics of the sample in which the research was conducted is shown in Table 1.

\begin{tabular}{|c|c|c|c|}
\hline Variables & Categories & f & $\%$ \\
\hline \multirow{5}{*}{ University } & Bülent Ecevit University & 80 & 19,7 \\
\hline & Kastamonu University & 71 & 17,4 \\
\hline & Karabük University & 82 & 20,1 \\
\hline & $\begin{array}{l}\text { Abant İzzet Baysal } \\
\text { University }\end{array}$ & 89 & 21,9 \\
\hline & Bartın University & 85 & 20,9 \\
\hline \multirow{2}{*}{ Sex } & Female & 155 & 38,1 \\
\hline & Male & 252 & 61,9 \\
\hline \multirow{4}{*}{ Grade } & 1. & 26 & 6,4 \\
\hline & 2. & 116 & 28,5 \\
\hline & 3. & 163 & 40,0 \\
\hline & 4. & 102 & 25,1 \\
\hline \multirow{3}{*}{ General Academic Average } & 2.50 and below & 56 & 13,8 \\
\hline & $2.51-3.00$ & 197 & 48,4 \\
\hline & 3.01 and above & 154 & 37,8 \\
\hline \multirow{3}{*}{ Family level of income } & Low & 48 & 11,8 \\
\hline & Middle & 315 & 77,4 \\
\hline & High & 44 & 10,8 \\
\hline Total & & 407 & 100,0 \\
\hline
\end{tabular}

As can be seen in Table 1, pre-service physical education teachers whose opinions were taken within the scope of the research; 19.7\% $(\mathrm{n}=80)$ in Bülent Ecevit University, $17.4 \%(\mathrm{n}=71)$ in Kastamonu University, $20.1 \%(\mathrm{n}=$ 82) in Karabük University, 21.9\% $(\mathrm{n}=89)$ in Abant İzzet Baysal University , 20.9\% $(\mathrm{n}=85)$ are studying at Bartın University. $38.1 \%(\mathrm{n}=155)$ of the pre-service teachers were female and $61.9 \%(\mathrm{n}=252)$ were malen. Participants; $6.4 \%(\mathrm{n}=26)$ were in the first grade, $28.5 \%(\mathrm{n}=116)$ in the second grade, $40.0 \%(\mathrm{n}=163)$ in the third grade, $25.1 \%(\mathrm{n}=102)$ in the fourth grade. $\mathrm{t}$ was found that $13.8 \%(\mathrm{n}=56)$ of the pre-service teachers had a GPA of 2.50 and below, $48.4 \%(\mathrm{n}=197)$ were between $2.51-3.00$ and $37.8 \%(\mathrm{n}=154) 3.01$ and above. It was determined that $11.8 \%(\mathrm{n}=48)$ of the pre-service teachers who participated in the study had low income, $77.4 \%(\mathrm{n}=315)$ had medium income, and $10.8 \%(\mathrm{n}=44)$ had high income.

\subsection{Data Collection Tool}

The data of this research was collected by Personal Information Form and Multicultural Perception Scale.

\subsection{Personal Information Form}

Personal information form was prepared for each variable in accordance with the purpose of the study in order to obtain information about the pre-service pre-service physical education teachers participating university, gender, grade level, general academic achievement grade point average and family income level.

\subsection{Multicultural Perception Scale}

Within the scope of the research, the Multicultural Perception Scale developed by Ayaz (2016) was used to determine the multicultural perception levels of pre-service physical education teachers. There are 25 items in the 
scale and the items are rated as 5-point Likert type. In the development process of the scale, 29 items were prepared and 3 items were removed from the draft scale in accordance with expert opinions. Then, the scale was applied to 194 pre-service teachers and exploratory factor analysis and then confirmatory factor analysis were conducted according to the answers of the pre-service teachers. As a result of exploratory factor analysis, an item less than 0.30 was excluded from the scale and the factor load values of the remaining 25 items varied between 0.389 and 0.809 . It was determined that the items in the scale were collected under a single factor. Subsequent confirmatory factor analysis showed that 25 items were collected in one dimension $(\mathrm{X} 2 / \mathrm{df}=3.4$; RMSEA $=$ 0.076; GFI $=0.85$; CFI $=0.97$; AGFI $=0.86$ ). After determining the construct validity of the scale, the criterion validity was examined and the correlation with a similar scale was calculated as 0.74 . In order to determine the reliability of the answers given by the pre-service teachers to the scale items, Cronbach alpha coefficient was calculated as 0.942; Spearman-Brown correlation coefficient was 0.882; Guttman Split-Half coefficient was calculated as 0.882. The obtained values showed that the scale was valid and reliable (Ayaz, 2016).

The aim of this study was to determine the multicultural perception levels of pre-service physical education teachers. Cronbach's alpha internal consistency coefficient was calculated as 0.894 in order to determine the reliability of the answers given to the scale items of 407 pre-service teachers whose opinions were taken within the scope of the research. The calculated value shows that pre-service physical education teachers have highly reliable responses to scale items (Kalaycı, 2009).

There are 25 items in 5-point Likert-type in the Multicultural Perception Scale. The score that can be obtained from the scale is in the range of 25-125. The whole scale consists of positive expressions. 25-50 points indicate that multicultural perceptions are low, 51-75 points are moderate and 76-100 points are high.

\subsection{Analysis of Data}

Within the scope of the research, firstly the answers obtained from the pre-service teachers were transferred to SPSS 23.0 program and it was determined whether there were missing and incorrect data entries. After the data analysis, the total scores of the pre-service teachers towards multicultural perceptions were calculated and outlier analysis was conducted. It was extracted from the 3 outlier data observation data sets. Then, skewness and kurtosis coefficients were calculated for the purpose of normality analysis. The coefficient of skewness was -0.707 and kurtosis was 0.978. Büyüköztürk (2008) states that skewness-kurtosis coefficients between \pm 1 indicate that the data set is normally distributed. In addition, a histogram graph was created and it was determined that the data set did not deviate from the normal distribution as shown in Figure 1.

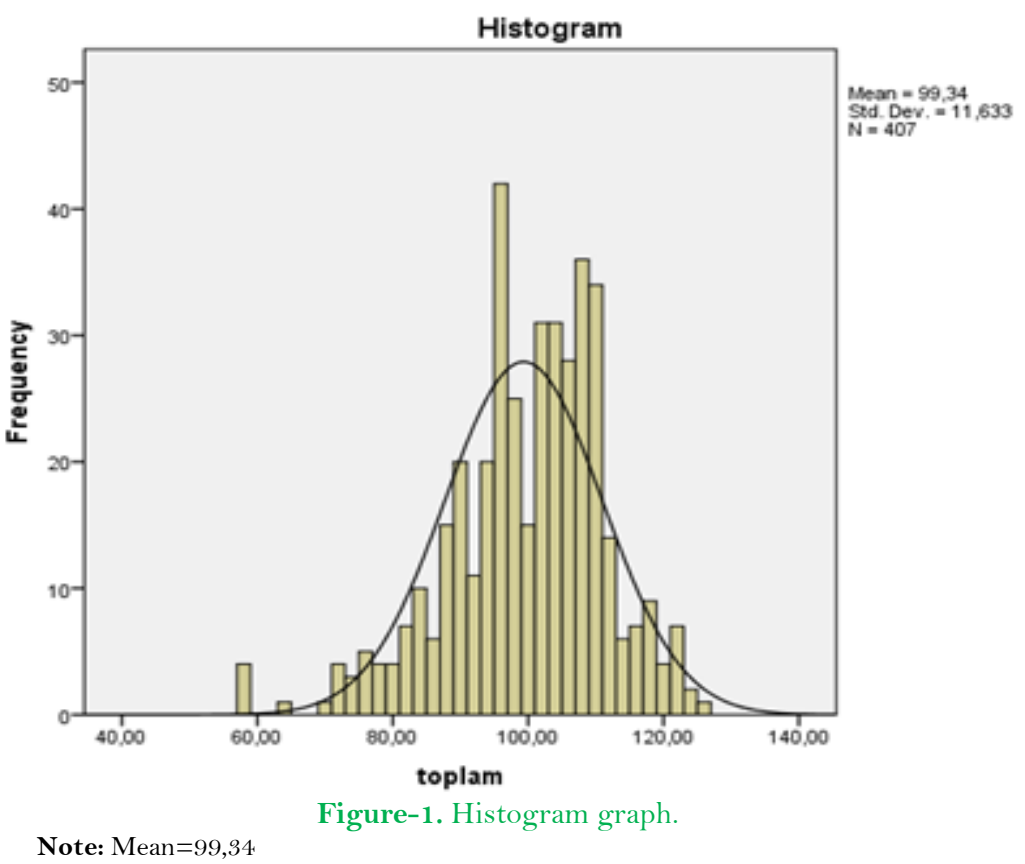

After analyzing the data set, descriptive statistics, minimum, maximum, mean and standard deviation values were calculated in line with the answers obtained from pre-service physical education teachers. In order to determine whether the pre-service teachers' perceptions of multiculturalism show a significant difference according to their gender, t-test was used for unrelated measurements. Since the variances were not homogeneous $(p<0.05)$, Kruskal Wallis test was used in the comparisons. In case of significant differences, multiple comparisons Tamhane's test was calculated. For significance, $\mathrm{p}<0.05$ was determined.

\section{Findings}

3.1. What is the Level of Multicultural Perception of Pre-Service Physical Education Teachers in the Western Black Sea Region?

Descriptive statistics were calculated in order to determine the multicultural perception levels of pre-service physical education teachers and the results are shown in Table 2.

Table-2. Descriptive statistics for the pre-service pre-service physical education teachers' multicultural perception levels.

\begin{tabular}{c|c|c|c|c|c}
\hline Scale & N & Min & Max & $\overline{\mathbf{X}}$ & SS \\
\hline Multicultural Perception & 407 & 58,00 & 125,00 & 99,34 & 11,63 \\
\hline
\end{tabular}

Note: $\overline{\mathbf{X}}=99,34$ 
When the information in Table 2 is examined, it is seen that the pre-service physical education teachers' multicultural perception scores range from 58.00 to 125.00 . The mean of multicultural perception of pre-service teachers was calculated as $99.34( \pm 11.63)$. The mean value shows that physical education teachers' perceptions of multiculturalism are high.

Do the pre-service physical education teachers in the Western Black Sea Region have a significant change in their perceptions of multiculturalism according to some characteristics?

It has been examined whether pre-service physical education teachers' multicultural perception levels show a significant difference to the university, gender, family income level, grade level and general academic achievement grade averages.

\subsection{According to University Variable}

Kruskal Wallis test was calculated for the pre-service physical education teacher in the Western Black Sea Region according to their perceptions of multiculturalism. The results are shown in Table 3.

Table-3. Kruskal Wallis test for the pre-service physical education teachers' multicultural perception levels according to the university they are studying.

\begin{tabular}{|c|c|c|c|c|c|c|c|}
\hline Variables & & $\mathbf{N}$ & $\overline{\bar{X}}$ & $\mathbf{S}_{\mathbf{x}}$ & Rank Sum & $\mathrm{X}^{2}$ & $\mathbf{p}$ \\
\hline \multirow{5}{*}{ University } & Bülent Ecevit University & 80 & 98,39 & 13,79 & 195,73 & \multirow{5}{*}{18,477} & \multirow{5}{*}{$0,001 *$} \\
\hline & Kastamonu University & 71 & 95,42 & 10,31 & 156,11 & & \\
\hline & Karabük University & 82 & 102,39 & 10,35 & 233,55 & & \\
\hline & Abant İzzet Baysal University & 89 & 99,56 & 13,21 & 213,04 & & \\
\hline & Bartın University & 85 & 100,35 & 8,74 & 213,81 & & \\
\hline
\end{tabular}

When Table 3 is examined, it is seen that pre-service physical education teachers' multicultural perception levels differ significantly according to the university (X2 $(4)=18,477 ; \mathrm{p}<0.05)$. As a result of the multiple comparison Tamhane's test, which was calculated to determine the meaningful difference, the multicultural perception levels of pre-service physical education teachers $(95,42 \pm 10,31)$ at Kastamonu University were found to be significantly lower than Bartın University (100.35 \pm 8.74) and Karabük University (102.39 \pm 10.35$)$.

\subsection{According to Sex}

In order to determine whether the pre-service physical education teachers' perceptions of multiculturalism show a significant change according to their gender, t-test was used. The results are shown in Table 4.

Table-4. The $\mathrm{t}$ test of unrelated measures calculated for the pre-service physical education teachers' multicultural perception levels according to their gender.

\begin{tabular}{l|l|c|c|c|c|c|c|c}
\hline Variables & & $\mathbf{N}$ & $\overline{\mathbf{X}}$ & $\mathbf{S}_{\mathbf{x}}$ & $\mathbf{d f}$ & $\mathbf{t}$ & $\mathbf{p}$ \\
\hline \multirow{2}{*}{ Sex } & Female & 155 & 99,12 & 9,20 & \multirow{2}{*}{405} & \multirow{2}{*}{0,301} & \multirow{2}{*}{0,764} \\
\cline { 2 - 6 } & Male & 252 & 99,48 & 12,92 & & \\
\hline
\end{tabular}

Note: $\quad \mathrm{P}>0,05$

According to the information in Table 4, it was determined that the pre-service physical education teachers' multicultural perception levels did not change significantly according to their gender $(t(405)=0.301 ; p>0.05)$. In other words, it was found that the perception of multiculturalism of male and female pre-service teachers was similar.

\subsection{According to Class Level}

Kruskal Wallis test was used for the perception of multiculturalism according to class levels of pre-service physical education teaches studying in the Western Black Sea Region. The results are shown in Table 5.

Table-5. Kruskal Wallis test calculated for the multicultural perception levels of pre-service physical education teachers according to class levels.

\begin{tabular}{|c|c|c|c|c|c|c|c|}
\hline Variables & & $\mathbf{N}$ & $\overline{\mathbf{X}}$ & $\mathbf{S}_{\mathbf{x}}$ & $\begin{array}{c}\text { Rank } \\
\text { Sum }\end{array}$ & $\mathbf{X}^{2}$ & $\mathbf{p}$ \\
\hline \multirow{4}{*}{ Class Levels } & 1. & 26 & 98,38 & 10,60 & 193,63 & \multirow{4}{*}{5,738} & \multirow{4}{*}{0,125} \\
\hline & 2. & 116 & 101,42 & 11,98 & 226,10 & & \\
\hline & 3. & 163 & 98,31 & 12,82 & 195,49 & & \\
\hline & 4. & 102 & 98,88 & 9,05 & 195,11 & & \\
\hline
\end{tabular}

Note: $\mathrm{P}>0,05$

According to the information given in Table 5, it was found that the levels of multicultural perception of preservice physical education teacher did not show a significant change according to class levels (X2 (3) $=5,738 ; \mathrm{p}$ $<0.05)$. In other words, multicultural perception levels of first, second, third and fourth grade pre-service teachers were found to be similar.

\subsection{According to General Academic Average}

The Kruskal Wallis test on the perceptions of multicultural students according to the general academic average point of pre-service physical education teachers studying in the Western Black Sea Region was calculated and the results are shown in Table 6. 
Table-6. Kruskal Wallis test calculated for the multicultural perception levels of pre-service physical education teachers according to the general academic average point.

\begin{tabular}{|c|c|c|c|c|c|c|c|}
\hline Variables & & $\mathbf{N}$ & $\overline{\mathbf{X}}$ & $\mathbf{S}_{\mathbf{x}}$ & $\begin{array}{c}\text { Rank } \\
\text { Sum }\end{array}$ & $\mathbf{X}^{2}$ & $\mathbf{p}$ \\
\hline \multirow{3}{*}{$\begin{array}{c}\text { General } \\
\text { Academic } \\
\text { Average }\end{array}$} & 2.50 and below & 56 & 95,68 & 11,70 & 164,05 & \multirow{3}{*}{12,516} & \multirow{3}{*}{$0,002^{*}$} \\
\hline & $2.51-3.00$ & 197 & 98,38 & 12,98 & 197,94 & & \\
\hline & 3.00 above & 154 & 101,92 & 9,01 & 226,27 & & \\
\hline
\end{tabular}

Note: $\mathrm{P}<0,05$

When the information in Table 6 was examined, it was determined that the perception levels of multiculturalism showed a significant change according to the general academic average $\left(\mathrm{X}_{2}(2)=12.516 ; \mathrm{p}\right.$ $<0.05)$. Tamhane's multiple comparison test was calculated to determine the difference. As a result of the calculation, the pre-service physical education teachers whose academic general academic average point is less than $2.50(95.68 \pm 11.70)$ was found to be significantly lower than those with general academic average over 3.00 $(101.92 \pm 9.01)$.

\subsection{According to Family Income Level}

Kruskal Wallis test for the perception of multiculturalism according to the income level of the pre-service teachers' family was calculated and the results are shown in Table 7.

Table-7. Kruskal Wallis test calculated for multicultural perception levels of pre-service physical education teacher according to their income level.

\begin{tabular}{|c|c|c|c|c|c|c|c|}
\hline Variables & & $\mathbf{N}$ & $\overline{\mathbf{X}}$ & $\mathbf{S}_{\mathbf{x}}$ & $\begin{array}{c}\text { Rank } \\
\text { Sum }\end{array}$ & $\mathbf{X}^{2}$ & $\mathbf{p}$ \\
\hline \multirow{3}{*}{$\begin{array}{c}\text { Family income } \\
\text { level }\end{array}$} & Low & 48 & 100,98 & 11,26 & 48 & \multirow{3}{*}{8,772} & \multirow{3}{*}{$0,012^{*}$} \\
\hline & Middle & 315 & 98,63 & 11,61 & 315 & & \\
\hline & High & 44 & 102,64 & 11,68 & 44 & & \\
\hline
\end{tabular}

Note: $\mathrm{P}<0,05$

As can be seen in Table 7, the multicultural perception of pre-service physical education teachers shows a significant change according to the income level of their families (X2 (2) = 8,772; $\mathrm{p}<0.05$ ). According to the multivariate Tamhane test, which was calculated in order to determine the difference, the pre-service teachers' with middle income level multicultural perception $(98.63 \pm 11.61)$ was found to be significantly lower than those with high income level (102.64 \pm 11.68$)$.

\section{Discussion and Conclusion}

Within the scope of this research, it has been investigated to determine the multicultural perception levels of pre-service physical education teachers studying in the Western Black Sea Region and whether the multicultural perception levels show a significant change according to some characteristics of pre-service physical education teachers. In this study, which is a quantitative research design, a total of 407 pre-service teachers studying at universities with Physical Education Teaching Department in Western Black Sea Region were included in the study.

Within the scope of the research, it was found that the pre-service physical education teachers' perceptions of multiculturalism were high. Banks (2014) expresses the perception of multiculturalism as providing equal opportunities to all people regardless of their gender, social status, ethnic or cultural characteristics. In this respect, it can be seen that pre-service physical education teachers studying in the Western Black Sea Region can offer equal opportunities for students of different cultures in the school environment. As a matter of fact, the success of multicultural education depends on the high level of multicultural perception of teachers (Gay, 2002). In an experimental study, McNeal (2005) concluded that teachers who received the multicultural teacher training program were more successful in their practices and contributed to the teachers' school environment and personal development. As a result of the research, it has been determined that multicultural education in schools is beneficial for teachers as well as students.

Karaçam and Koca (2012) in the qualitative study conducted with nine pre-service physical education teachers studying at three universities in Ankara during the 2010-2011 academic year, stated that pre-service physical education teachers had low level of multicultural awareness. Başbay and Bektaş (2009) also stated that in general, pre-service teachers had deficiencies in this subject and that they should acquire multicultural awareness, knowledge and skills during the teaching process. Milner (2006) states that teachers started to work without awareness of multiculturalism. Within the scope of this research, it was determined that the awareness of preservice physical education teachers was high. This may be due to the increase in the social sensitivity and awareness of the individuals over time as well as the diversity of the working group. In other studies conducted in the literature, teachers, students or principals have a high perception of multiculturalism; this situation is connected to the implicit multicultural education of individuals in the process of pedagogical education. As a matter of fact, Toprak (2008) showed that teachers' perspectives on multiculturalism were positive. Demir (2012) in a similar way, showed that the perspectives of faculty members towards multicultural education were positive. Kaya. (2013) in his study conducted with class teachers, social studies teachers and Turkish teachers working in Diyarbakır, revealed that teachers' perceptions of multiculturalism were positive. Bahadır (2016) found that $90 \%$ of teachers' perceptions of multiculturalism and multicultural education were positive in their study conducted with qualitative research methodology with social studies teachers. Ates (2017) examined multicultural citizen perception and awareness of both secondary school students and social studies teachers and found that students' perceptions about multiculturalism were positive. Arsal et al. (2017) found that pre-service teachers' beliefs and 
attitudes towards multicultural education were positive. Mazı (2018) stated that teachers' perceptions of multiculturalism were high in their study conducted with teachers from different branches.

Physical education and sport have a common language and it is against the nature of sport to distinguish students according to any ethnic, social, gender, etc. Physical education teachers' perceptions of multiculturalism are high, if they are considered as an indicator that they will be aware of this awareness of physical education teachers can be said to be multicultural awareness. Pre-service physical education teachers' perception of multiculturalism is high and it is considered that they will be in this consciousness when they become teachers, it can be said that physical education teachers will train with multicultural awareness.

Pre-service physical education teachers' perceptions of multiculturalism showed a significant change compared to the universities they studied; It was determined that the pre-service teachers of Kastamonu University were significantly lower than those of Bartın and Karabük University. In this respect, qualitative studies can be planned in order to examine the curriculum in detail and to obtain detailed views of pre-service teachers.

It was found that the pre-service physical education teachers' perceptions of multiculturalism did not show a significant difference according to their gender. Kaya. (2013) found that teachers' opinions about multiculturalism did not show a significant difference according to their gender in their study conducted with different branch teachers. Similarly, Bahadır (2016) revealed that there were no significant differences between the attitudes of teachers towards multicultural education according to their gender. Ates (2017) also revealed that social studies teachers' perceptions of multicultural education of male and female were similar. Akman and Imamoğlu (2017) state that teachers' attitudes towards multicultural education do not change significantly according to their gender. Similarly, Mazı (2018) found that multiculturalism perceptions of teachers working in different branches show similarities. Physical education teachers' perceptions of multiculturalism differ according to their gender, and they can be considered as an indicator that their students will be educated by considering different cultural characteristics, especially gender.

It was found that the pre-service teachers' perceptions of multiculturalism did not show a significant difference according to their class level. It may have led to the similarity of multicultural education according to class levels of pre-service teachers who met sport at a young age.

It was determined that pre-service physical education teachers' perceptions of multiculturalism showed a significant change according to their general academic grade point averages. It has been found that the students who have an academic general academic grade point average above 3.00 are significantly higher than the preservice teachers whose multicultural perceptions are below 2.50. This may be an indication of implicit multicultural education in the curriculum, or may be due to the pre-service teachers' sense of success and belonging in the department, and their future plans.

According to the research, it was found that the perceptions of the pre-service physical education teachers whose opinions were taken according to the income level of the families showed a significant change and the preservice teachers with high incomes were significantly higher than the middle ones. Ates (2017) in his study conducted with secondary school students, found that students' perceptions of multiculturalism showed a significant change according to the economic status of their families, and the perceptions of students with high income levels were more positive. Students with high incomes are more likely to meet different social environments and groups such as artistic activities such as cinema and theater. In this respect, as the income levels of individuals increase, it is likely that they will be more likely to participate in different groups, to recognize them and to provide them with tolerance.

In this study, pre-service physical education teachers' perception of multiculturalism was examined. The preservice teachers' competencies for multicultural education and their ability to apply education can be examined in other studies. This study, which took place in the Western Black Sea sample, can be repeated in other regions and the results can be compared with the results obtained from this study. In universities, multicultural education is offered to pre-service teachers in an implicit program. Considering the differences in the views of pre-service teachers on the basis of universities, it may be suggested to include a course in this direction in the curriculum. By organizing activities in which pre-service teachers can come together with different social groups, it can be ensured that they develop positive opinions for people with different status.

\section{References}

Akman, Y., \& Imamoğlu, A. G. (2017). Investigation of teachers' multicultural education attitude according to their perception of social intelligence. Sakarya University Journal of Education, 7(1), 34-48.

Arsal, Z., Mumcu, A. D., \& Akçaoğlu, M. (2017). Multicultural experience, attitudes and beliefs of music teacher candidates. Abant Izzet Baysal University Faculty of Education Journal, 17(1), 17- 31.

Aslan, M., \& Kozikoğlu, İ. (2017). Teachers' attitudes towards multicultural education: Van province example. Dicle University Journal of Ziya Gokalp Faculty of Education, 31, 729-737.

Ates, S. (2017). Perceptions and awareness of social studies teachers and secondary school students towards multiculturalism and multicultural education (Kocaeli example). Master's Thesis, Abant İzzet Baysal University Faculty of Educational Sciences, Bolu.

Ayaz, M. F. (2016). Multiculturalism perception scale: Validity and reliability study. Electronic Journal of Social Sciences, 15(57), 463-471.

Bahadır, O. (2016). Evaluation of social studies teachers' multiculturalism and multicultural education perceptions: Kocaeli example. Master Thesis, Sakarya University Institute of Educational Sciences, Sakarya.

Banks, J. A. (2014). Introduction to multicultural education, (Trans. H. Aydın). Ankara: AnıYıncılık.

Banks., J. A. (1993). Chapter 1: Multicultural education: Historical development, dimensions, and practice. Review of Research in Education, 19(1), 3-49. Available at: https://doi.org/10.3102/0091732x019001003.

Başbay, A., \& Bektaş, Y. (2009). Teaching environment and teacher competencies in the context of multiculturalism. Education and Science, $34(152), 30-43$.

Başbay, A., \& Kağnıcı, Y. (2011). Multicultural competency perceptions scale: A scale development study. Education and Science, 36(161), 199212 .

Büyüköztürk, S. (2008). Data analysis handbook for social sciences: Statistics, research design, SPSS applications and interpretation. Ankara: PegemA Publishing.

Büyüköztürk, S., Cakmak, E. K., Akgün, O. E., Karadeniz, S., \& Demirel, F. (2018). Scientific research methods. Ankara: PegemA Publishing.

Cirik, R. (2008). Multicultural education and its reflections. Hacettepe University Faculty of Education Journal (H. U. Journal of Education, 34, 27-40. 
Demir, S. (2012). The degree of importance of multicultural education for erciyes university lecturers. International Periodical For The Languages, Literature and History of Turkish or Turkic, 7(4), 1453-1475.

Ertürk, S. (1997). Program development in education. Ankara: Meteksan.

Frankel, J. R., \& Wallen, N. E. (2009). How to design and evaluate research ın education. New York: McGraw-Hill İnternational Edition.

Gay, G. (2002). Preparing for culturally responsive teaching. Journal of Teacher Education, 53(2), 106-116. Available at: https://doi.org/10.1177/0022487102053002003.

Gonzalez, J. M. (2008). Encyclopedia of bilingual education. Los Angeles: Sage.

Kalaycı, Ş. (2009). SPSS applications multivariate statistical techniques (5th ed.). Ankara: Asil Publishing.

Karaçam, M. S., \& Koca, C. (2012). Multicultural awareness of pre-service teachers. Hacettepe Journal of Social Sciences, 23(3), 89-103.

Karasar, N. (2008). Scientific research method. Ankara: Nobel Publishing.

Kaya, I., \& Aydin, H. (2013). Problem of education in the mother tongue in Turkey: Challenges, experiences and bilingual education model recommendations. Istanbul: Ukam.

Kaya., Y. (2013). Determining the opinions of teachers about multiculturalism and multicultural education (Diyarbakir example). Master Thesis, Dicle University Institute of Educational Sciences, Diyarbakir.

Koçak, S., \& Ozdemir, M. (2015). The role of cultural intelligence in teacher candidates' attitudes towards multicultural education. Elementary Education Online Journal, 14(4), 1352-1369.

Mazı, A. (2018). Investigation of teachers' multicultural perceptions: An example of Hatay province. Master Thesis, Kahramanmaraş Sütçü İmam University Institute of Social Sciences, Kahramanmaraş.

McNeal, K. (2005). The influence of a multicultural teacher education program on teachers' multicultural practices. Intercultural Education, 16(4), 405-419. Available at: https://doi.org/10.1080/14675980500304405.

Milner, H. R. (2006). Preservice teachers' learning about cultural and racial diversity: Implications for urban education. Urban Education, 41(4), 343-375. Available at: https://doi.org/10.1177/0042085906289709.

Parekh, B. (2002). Rethinking multiculturalism, cultural diversity and political theory, (Trans. Bilge Tanriseven). Ankara: Phoenix Publishing House.

Portera, A. (2008). Intercultural education in Europe: Epistemological and semantic aspects. Intercultural Education, 19(6), 481-491. Available at: https://doi.org/10.1080/14675980802568277.

Toprak, G. (2008). Reliability and validity study of teachers' multicultural attitude scale. Master Thesis, Gaziosmanpaşa University Institute of Social Sciences, Tokat.

Uygur, N. (1996). Cultural theory. Istanbul: Remzi Bookstore. 